\title{
A New Generation Somatostatin-Dopamine Analogue Exerts Potent Antitumoral Actions on Pituitary Neuroendocrine Tumor Cells
}

\author{
Mari C. Vázquez-Borrego ${ }^{\text {a-d }}$ Fernando L-López ${ }^{a-d} \quad$ María A. Gálvez-Moreno $^{\text {a-c, e }}$ \\ Antonio C. Fuentes-Fayos ${ }^{a-d}$ Eva Venegas-Moreno ${ }^{f} \quad$ Aura D. Herrera-Martínez $^{a, c, e}$ \\ Cristóbal Blanco-Acevedo ${ }^{\text {a,c,g }}$ Juan Solivera ${ }^{a, c, g}$ Tanya Landsman ${ }^{\mathrm{h}}$ \\ Manuel D. Gahete ${ }^{a-d}$ Alfonso Soto-Morenof Michael D. Culler ${ }^{\text {h }}$ \\ Justo P. Castaño ${ }^{a-d}$ Raúl M. Luque ${ }^{a-d}$ \\ ${ }^{a}$ Maimonides Institute of Biomedical Research of Cordoba (IMIBIC), Cordoba, Spain; ${ }^{b}$ Department of Cell Biology, \\ Physiology and Immunology, University of Cordoba, Cordoba, Spain; ' ${ }^{\mathrm{R}}$ Reina Sofia University Hospital (HURS),

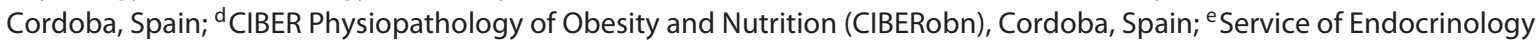 \\ and Nutrition, IMIBIC, HURS, Cordoba, Spain; ' Metabolism and Nutrition Unit, Hospital Universitario Virgen del Rocío, \\ Instituto de Biomedicina de Sevilla (IBIS), Sevilla, Spain; ${ }^{9}$ Service of Neurosurgery, HURS, Cordoba, Spain; \\ hIPSEN Bioscience, Cambridge, MA, USA
}

\section{Keywords}

Pituitary neuroendocrine tumors · Chimeric compound ·

Somatostatin · Dopamine $\cdot$ Receptor

\begin{abstract}
Background: Pituitary neuroendocrine tumors (PitNETs) represent approximately $15 \%$ of all intracranial tumors and usually are associated with severe comorbidities. Unfortunately, a relevant number of patients do not respond to currently available pharmacological treatments, that is, somatostatin analogs (SSAs) or dopamine-agonists (DA). Thus, novel, chimeric somatostatin/dopamine compounds (dopastatins) that could improve medical treatment of PitNETs have been designed. Objective: This study aims to determine the direct therapeutic effects of a new-generation dopastatin, BIM-065, on primary cell cultures from different PitNETs subtypes. Methods: Thirty-one PitNET-derived cell cultures (9 corticotropinomas, 9 somatotropinomas, 11 non-
\end{abstract}

functioning pituitary adenomas [NFPAs], and 2 prolactinomas), were treated with BIM-065, and key functional endpoints were assessed (cell viability, apoptosis, hormone secretion, expression levels of key genes, free cytosolic $\left[\mathrm{Ca}^{2+}\right]_{i}$ dynamics, etc.). AtT-20 cell line was used to evaluate signaling pathways in response to BIM-065. Results: This chimeric compound decreased cell viability in all corticotropinomas and somatotropinomas tested, but not in NFPAs. BIM-065 reduced $A C T H, G H$, chromogranin- $A$ and $P R L$ secretion, and increased apoptosis in corticotropinomas, somatotropinomas, and NFPAs. These effects were possibly mediated through modulation of pivotal signaling cascades like $\left[\mathrm{Ca}^{2+}\right]_{\mathrm{i}}$ kinetic and Akt- or ERK1/2-phosphorylation. Conclusions: Our results unveil a robust antitumoral effect in vitro of the novel chimeric compound BIM-065 on the main PitNET sub-

T.L. and M.D.C. have different current affiliations.

\section{KARGER}

(c) 2019 S. Karger AG, Basel

E-Mail karger@karger.com

www.karger.com/nen
Raúl M. Luque and Justo P. Castaño

Maimonides Institute of Biomedical Research of Cordoba (IMIBIC), Department of Cell Biology, Physiology and Immunology, University of Cordoba

Menendez Pidal s/n, First Floor, ES-14004 Cordoba (Spain)

E-Mail raul.luque@uco.es and justo@uco.es 
types, inform on the mechanisms involved, and suggest that BIM-065 could be an efficacious therapeutic option to be considered in the treatment of PitNETs.

(C) 2019 S. Karger AG, Basel

\section{Introduction}

Pituitary neuroendocrine tumors (PitNETs) are mostly benign neuroendocrine neoplasms confined to the sella turcica that constitute approximately $15 \%$ of all intracranial tumors $[1,2]$. These tumors are usually monoclonal, derived from the expansion of single precursor cells, and are associated with severe comorbidities related to hormonal hypersecretion and/or mass effects, such as hypopituitarism, visual defects, amenorrhea, galactorrhea, sexual dysfunctions, and growth abnormalities [3-5]. The expression of somatostatin and dopamine receptors (SST $\mathrm{S}_{1-5}$ and $\mathrm{D}_{1-5}$, respectively) has been largely studied in the different PitNETs subtypes, wherein high levels of certain SSTs/Ds, especially SST $2, \mathrm{SST}_{5}$, and $\mathrm{D}_{2}$, have been described [6-10]. For this reason, somatostatin analogs (SSAs: i.e., octreotide, pasireotide, and lanreotide) and dopamine agonists (DA; i.e., cabergoline and bromocriptine) have been widely used as pharmacological treatments to manage this and other endocrine-related pathologies due to their multiple antiproliferative and antisecretory actions $[6,11,12]$. Nevertheless, numerous reports have demonstrated that a high proportion of patients are unable to respond to these treatments, or that the responses show a high variability or decline over time [12-14]. Inasmuch as PitNETs often express, simultaneously, high levels of various SSTs and Ds, and both families of receptors have the capacity of heterodimerize resulting in altered pharmacological properties $[15,16]$, new chimeric somatostatin (SRIF)/DA compounds were developed in order to increase their efficacy and improve the control of the disease compared with individual SSA and/or DA [17].

In this context, BIM-23A760, a chimeric compound able to bind $\mathrm{SST}_{2}, \mathrm{SST}_{5}$, and $\mathrm{D}_{2}$ with high affinity, was considered a promising therapeutic option to treat different PitNETs subtypes. In fact, the direct effects of this chimeric compound have been tested in different normal and tumoral pituitary cell models [8, 18-24]. Recently, our group has demonstrated that treatment with BIM23A760 reduce hormone secretion and/or expression in a set of somatotropinomas (GHomas), prolactinomas (PRLomas), and corticotropinomas (ACTHomas) [8]. However, these results also showed the existence of two
PitNET cell populations that oppositely responded to the treatment of BIM-23A760, an inhibitory- and stimulatory population [8], suggesting that this compound might not be a successful therapeutic option in some patients with PAs. Moreover, BIM-23A760 has been finally withdrawn from clinical development after discovering a dopaminergic metabolite that accumulates and interferes with the activity of the parent compound in vivo [17].

For all these reasons, a new generation of chimeric agonist for $\mathrm{SST}_{2} / \mathrm{SST}_{5} / \mathrm{D}_{2}$ receptors (named BIM-065), with higher potency, efficacy, and safety, has been recently designed and developed by IPSEN that may be used for clinical purposes in the future $[25,26]$. Therefore, the main aim of this study was to evaluate, for the first time, the direct effects of this new compound on relevant functional parameters (cell viability, apoptosis, hormonal secretion/expression, and $\left[\mathrm{Ca}^{2+}\right]_{i}$ kinetics) in primary cell cultures from different PitNETs, including ACTHomas, GHomas, nonfunctioning pituitary adenomas (NFPAs), and PRLomas.

\section{Materials and Methods}

\section{Reagents}

All reagents used in this study were purchased from SigmaAldrich (St. Louis, MO, USA) unless otherwise specified. BIM-065 and cabergoline were kindly provided by IPSEN Bioscience (Cambridge, MA, USA) and prepared following the instructions of the company. Octreotide was obtained from GP-Pharm (Barcelona, Spain), and pasireotide was generously provided by Novartis. All compounds were used at $100 \mathrm{nM}$ based on previous studies $[8,27$, $28]$.

Patients, Samples, and Primary Cell Cultures

Human PitNETs were obtained during transsphenoidal surgery from a total of 31 patients: 9 ACTHomas (mean age: 51 [2979] years; 67\% women), 9 GHomas (mean age: 48 [29-63] years; $44 \%$ women), 2 PRLomas (mean age: 25 [20-30] years; 50\% women), and 11 NFPAs (mean age: 56 [41-75] years; $45 \%$ women). The appropriate classification of each pituitary sample collected was confirmed by 2 different methods: examination by expert anatomo-pathologists and by the molecular screening using quantitative real-time PCR (qPCR) as previously described [8, 28-30]. All techniques carried out in this study were conducted in accordance with the ethical standards of the Helsinki Declaration of the World Medical Association and with the approval of the University of Cordoba/IMIBIC and Ethics Committees from all the Hospitals involved in the study. Informed consent from each patient was obtained.

All human samples were placed in sterile cold medium (SMEM, Gibco, Madrid, Spain) supplemented with 0.1\% BSA, 0.01\% L-glutamine, $1 \%$ antibiotic-antimycotic solution, and $2.5 \%$ 2-(4[2-hydroxyethyl]-1-piperazine)-ethane sulfonic acid. The samples were rapidly moved to our laboratory and dispersed into 
single cells by mechanical and enzymatic disruption and cultured onto different tissue culture plates following the methods and reagents previously described [28, 29].

\section{Cell Line and Culturing}

The mouse corticotroph pituitary derived cell line AtT-20/ D16v-F2 (ATCC ${ }^{\circledR}$ CRL-1795) was cultured and maintained in Dulbecco's Modified Eagle's Medium complemented with 10\% FBS, $100 \mathrm{U} / \mathrm{mL}$ penicillin/streptomycin, $0.024 \mathrm{M}$ of 2-(4[2hydroxyethyl]-1-piperazine)-ethane sulfonic acid, and maintained at $37^{\circ} \mathrm{C}$ and $5 \% \mathrm{CO}_{2}$, under sterile conditions, as previously reported [29]. The passage numbers used for the experiments were ranged between 20 and 25 . Additionally, both cell lines were checked for mycoplasma contamination by PCR [31].

\section{Measurement of Cell Viability}

Cell viability of PitNET cell cultures (10,000 cells/well in 96well plates) was evaluated every $24 \mathrm{~h}$ until $72 \mathrm{~h}$ in response to BIM065, octreotide, pasireotide, or cabergoline using Alamar-blue reagent (Invitrogen, Madrid, Spain). In experiments using AtT-20 cell line, 6,000 cells/well were seeded in 96-well plates. The treatment was daily refreshed after each measure. Reduction of Alamar-blue was quantified using a FlexStation III system (Molecular Devices, Sunnyvale, CA, USA), as previously reported [8, 30, 32].

\section{Measurement of Apoptotic Rate}

Apoptotic rate was determined by measuring caspase 3/7 activity in response to BIM-065 using the Caspase-Glo 3/7 assay (Promega, Madrid, Spain) according to manufacturer's instructions. Briefly, 25,000 cells/well were plated in a 96-well white microplate and cultured for $24 \mathrm{~h}$ at $37^{\circ} \mathrm{C}$ in an atmosphere containing $5 \%$ $\mathrm{CO}_{2}$. Then, cells were incubated for another $24 \mathrm{~h}$ with BIM-065 and vehicle. After the incubation period, $100 \mu \mathrm{L}$ of Caspase-Glo $3 / 7$ reagent was added to each well and luminescence was measured at room temperature using FlexStation III system (Molecular Devices, Sunnyvale, CA, USA) for $3 \mathrm{~h}$.

\section{Measurement of Pituitary Hormone Release}

To evaluate the effect of BIM-065 on pituitary hormone secretion, 150,000-200,000 cells/well were used. Media were recollected after $24 \mathrm{~h}$ of treatment and ACTH, GH, chromogranin-A (CgA), and PRL were evaluated using commercial ELISA kits (reference numbers: EIA-3647, EIA-3552, EIA-4937, and EIA-1291, respectively; DRG, Mountainside, NJ, USA) following the manufacturer's instructions. All the information regarding specificity, detectability, and reproducibility for each of the assays can be accessed at the website of the company.

\section{Measurement of Dynamics of Free Cytosolic Calcium}

Concentration $\left(\left[\mathrm{Ca}^{2+}\right]_{i}\right)$

To assess the direct effect of BIM-065 on free cytosolic calcium mobilization, 50,000 cells/coverslip were plated, and changes in $\left[\mathrm{Ca}^{2+}\right]_{\mathrm{i}}$ in single cells of all types of PitNETs were measured using fura-2AM (Molecular Probes, Eugene, OR, USA), as previously described $[8,29,30]$.

Measurement of MAPK and PI3K-Akt Signaling Pathways by Western Blotting

The mouse corticotroph PitNET-derived cell line AtT-20/ D16v-F2 (ATCC ${ }^{\circledR}$ CRL-1795) was used to further explore the sig- naling pathways modulated in response to BIM-065 due to the limited number of primary PitNET cells available for the culture experiments. About 500,000 cells were cultured in 6-well plates and incubated for $24 \mathrm{~h}$ with BIM-065 and vehicle-treated controls, as described previously [30]. Extracted protein samples were incubated with the primary antibodies (p-AKT [Ser47; Ref. CS9271S], Akt [Ref. CS9272], Bcl-2 [Ref. CS3498], p-ERK1/2 [Ref. CS4370], ERK1/2 [Ref. CS154], from Cell Signaling [Danvers, MA, USA]) and the appropriate secondary antibodies (secondary anti-rabbit antibody from Cell Signaling, Danvers, MA, USA), and developed using an enhanced chemiluminescence detection system (GE Healthcare, UK) with dyed molecular weight markers. A densitometric analysis of the bands was carried out with ImageJ software [33]. Relative phosphorylation of ERK1/2 and Akt was obtained from normalization of $\mathrm{p}$-ERK1/2 or p-Akt against the total ERK1/2 or p-Akt, respectively. Bcl-2 was normalized by using total protein loading (ponceau staining).

\section{RNA Isolation, Reverse Transcription, and Analysis of Gene} Expression Levels by $q P C R$

Details of RNA extraction, quantification, reverse-transcription (RT), and qPCR using specific primers included in this study have been previously reported elsewhere by our group $[8,30,34$, 35 ]. It should be mentioned that since it is not possible to design a specific set of primers for qPCR that only amplified the short isoform of $\mathrm{D}_{2}$, a set of primers that amplify both, the long and short, isoforms $\left(\mathrm{D}_{2} \mathrm{~T}\right)$ and a set of primers that only amplify the long isoform $\left(\mathrm{D}_{2} \mathrm{~L}\right)$ were used in this study, as previously reported [36]. In addition, new primer sequences were used in the present study to amplify CDKN1B (sense, ATAAGGAAGCGACCTGCAAC and antisense, TTGGGGAACCGTCTGAAA; accession number, NC_000012.12; product size, $88 \mathrm{pb}$ ) and CDK2 (sense, GCTCTCACTGGCATTCCTCTT and antisense, GAGGTTTAAGGTCTCGGTGGA; accession number, NC_000012.12; product size, $109 \mathrm{pb}$ ). It should be noted that, as previously reported and based on the stringent criteria to maximize specificity and efficiency, the qPCR technique, as applied, can be used to accurately quantify copy numbers for all human transcripts included in this study [36]. A no RT sample was used to ascertain that no detectable genomic DNA was present in the total RNA preparation. Moreover, to control for variations in the amount of RNA used in the $\mathrm{RT}$ reaction and the efficiency of the $\mathrm{RT}$ reaction, the expression level (copy-number) of each transcript was adjusted using a normalization factor (NF) calculated from beta actin, hypoxanthineguanine phosphoribosyltransferase 1, and glyceraldehyde 3-phosphate dehydrogenase expression levels.

\section{Statistical Analysis}

All data are expressed as mean \pm SEM. Statistical differences were assessed by paired parametric $t$ test or one-way ANOVA followed by Dunnett's test for multiple comparison (according to normality evaluated by Kolmogorov-Smirnov test). As previously reported [29], to normalize values within each treatment and minimize intragroup variations in the different in vitro experiments (i.e., different age of the tissue donor and metabolic environment), the values obtained were compared with vehicle-treated controls (set at 100\%). All experiments were performed in a minimum of 3 independent primary pituitary cultures from different patients (3-4 replicates/treatment per experiment), unless otherwise indicated. $p$ values $\leq 0.05$ were considered statistically significant and 
a trend for significance was indicated when $p$ values ranged between $>0.05$ and $<0.1$. All statistical analyses were performed using GraphPad Prism 6 (GraphPad Software; La Jolla, CA, USA).

\section{Results}

Expression Profile of $\mathrm{SST}_{2}, \mathrm{SST}_{5}$, and $\mathrm{D}_{2}$ and Effects of BIM-065 on ACTHomas

$\mathrm{SST}_{2}, \mathrm{SST}_{5}$, and $\mathrm{D}_{2}$, the target receptors for BIM-065, were highly expressed in human ACTHomas, with relative order of $\mathrm{D}_{2} \mathrm{~T}>\mathrm{D}_{2} \mathrm{~L}>\mathrm{SST}_{5}>>\mathrm{SST}_{2}$ (Fig. 1a), suggesting that corticotropinomas represent an appropriate model to test the effect of the new dopastatin compound. We also measured the expression of the two truncated $\mathrm{SST}_{5}$ variants, $\mathrm{SST}_{5} \mathrm{TMD} 4$ and $\mathrm{SST}_{5} \mathrm{TMD} 5$, since the presence of these isoforms have been associated to a poor response to SSAs [7, 37]; however, the expression levels of these truncated $\mathrm{SST}_{5}$ variants were negligible $(<10$ copies) in this cohort of samples.

Incubation of cultured ACTHoma cells with different doses of BIM-065 ( $10^{-9}$ to $\left.10^{-6} \mathrm{M}\right)$ revealed clear inhibitory effects on cell viability (Fig. 1b). Interestingly, the 4 doses employed reduced cell viability at similar levels after $48-72 \mathrm{~h}$ of incubation. It should be noted that, due to the limited number of cells available for the culture experiments, we could not test a wider range of doses; however, we had the opportunity to expand the doses employed in one ACTHoma cell preparation, in which a clear dose-response reduction on cell viability was observed at lower concentrations of BIM-065 $\left(10^{-13}\right.$ to $10^{-9} \mathrm{M}$; online suppl. Fig. 1A; for all online suppl. material, see www.karger.com/doi/10.1159/000500812). Specifically, BIM-065 does not seem to significantly alter cell viability at $10^{-13}$ or $10^{-11} \mathrm{M}$, whereas, as previously observed (Fig. 1b), it clearly reduced this parameter at $10^{-9}$ $\mathrm{M}$ after $72 \mathrm{~h}$ of incubation (online suppl. Fig. 1A). Based on these results and, in order to compare the effects of BIM-065 with previously selected, efficacious doses of SSAs (i.e., octreotide and pasireotide) and BIM-23A760 (the first-generation dopastatin compound) in PA cell cultures $[8,28]$, we selected the $10^{-7} \mathrm{M}$ dose in further experiments.

Our results indicated that BIM-065 and octreotide produced a comparable significant reduction on cell viability in ACTHoma cell cultures (31.1 vs. 26.1\%); however, pasireotide did not significantly alter cell viability (Fig. 1c). Interestingly, we could also compare the effects of BIM-065 and octreotide at a lower dose $\left(10^{-9} \mathrm{M}\right)$ in an ACTHoma cell preparation, and the results clearly indi- cated that BIM-065 seems to be more effective than octreotide in reducing cell-viability after $72 \mathrm{~h}$ of incubation (41 vs. 10\%, respectively; online suppl. Fig. 1B). In addition, we observed that incubation with BIM-065 $\left(10^{-7} \mathrm{M}\right)$ increased apoptosis after $24 \mathrm{~h}$ compared with vehicletreated controls (Fig. 1d). Moreover, BIM-065 also appeared to decrease ACTH release in all ACTHomas analyzed, although this difference did not reach statistical significance probably due to the limited number of samples ( $p=0.07$; Fig. 1e); whereas, it did not alter mRNA expression levels of POMC (ACTH-precursor), somatostatin, and dopamine receptors $\left(\mathrm{SST}_{2}, \mathrm{SST}_{5}, \mathrm{D}_{2} \mathrm{~T}, \mathrm{D}_{2} \mathrm{~L}\right.$; Fig. 1f) or tumor markers commonly associated with progression and aggressiveness of PitNETs such as PTTG1, CDKN1B, and CDK2 [38-40] (online suppl. Fig. 5A).

We also analyzed the direct effects of BIM-065 on $\left[\mathrm{Ca}^{2+}\right]_{\mathrm{i}}$ dynamics in single cells, since this is a key second messenger involved in the regulation of pituitary cell physiology and is closely related to hormone secretion through the modulation of secretory vesicle release [30, $41,42]$. This showed that BIM-065 treatment evoked a rapid inhibitory effect in the kinetics of $\left[\mathrm{Ca}^{2+}\right]_{i}$ in all ACTHomas cases analyzed (3/3), exhibiting an averaged $26.4 \%$ of reduction in $44 \%$ of responsive corticotropinoma cells (Fig. 1g). Finally, to further test the capacity of BIM-065 to induce functional responses in pituitary tumor cells, we measured the levels of phosphorylation of several components of two important signaling pathways (MAPK and PI3K-Akt) in the PitNET-derived cell line AtT-20 (Fig. 2). As previously observed in primary ACTHoma cell cultures, treatment with BIM-065 (10 M) markedly reduced cell proliferation in cultured AtT20 cells as compared to vehicle-treated controls (Fig. 2a). Interestingly, short-term incubation with BIM-065 (10 min) clearly increased $\mathrm{p}$-Akt $(p=0.004)$, which was followed by a clear reduction of the antiapoptotic protein Bcl-2 (Fig. 2b). In contrast, long-term incubation with BIM-065 (24 h) upregulated p-ERK1/2 levels, although this latter effect did not reach statistical significance $(p=$ 0.1 ; Fig. 2b).

Expression Profile of $S S T_{2}, S S T_{5}$, and $D_{2}$ and Effects of BIM-065 on GHomas

Similar to ACTHomas, $\mathrm{SST}_{2}, \mathrm{SST}_{5}$, and $\mathrm{D}_{2}$ were highly expressed in human GHomas, with relative order of $\mathrm{D}_{2} \mathrm{~T}>\mathrm{D}_{2} \mathrm{~L}>\mathrm{SST}_{5}>>\mathrm{SST}_{2}$ (Fig. 3a). This expression profile is consistent with previous results evaluating and comparing the mRNA levels and protein content $[43,44]$, therefore supporting that somatotropinomas also represent an appropriate model to test the effect of BIM-065. 



\begin{tabular}{c|ccc}
$\mathrm{Ca}^{2+}{ }_{i}$ & $\% \mathrm{PRC}$ & $\% \mathrm{PMR} \pm \mathrm{SEM}$ & Time, $\mathrm{s} \pm \mathrm{SEM}$ \\
\hline BIM-065 & $44 \%$ & $26.41 \pm 2.80$ & $9.42 \pm 0.91$
\end{tabular}

Fig. 1. ACTH-secreting adenomas. a Expression profile of $\mathrm{SST}_{2}$, $\mathrm{SST}_{5}, \mathrm{D}_{2}$ (total and long isoforms), $\mathrm{SST}_{5} \mathrm{TMD} 4$, and SST $\mathrm{TMD}_{5}$ $(n=5)$. $\mathbf{b}$ Dose-response experiment of cell viability in response to BIM-065 ( $10^{-9}$ to $\left.10^{-6} \mathrm{M} ; n=3\right)$. c Effect of BIM-065, octreotide, and pasireotide on cell viability $\left(10^{-7} \mathrm{M} ; n=3-6 ; 24-72 \mathrm{~h}\right.$ treatment). d Effect of BIM-065 ( $n=3)$ on apoptosis ( $24 \mathrm{~h}$ treatment). e Measurement of ACTH secretion ( $24 \mathrm{~h}$ treatment; $n=3$ ). f mRNA expression levels of key genes in response to BIM-065 measured by qPCR and adjusted by NF $(n=4)$. g Summarized table and representative profile of $\left[\mathrm{Ca}^{2+}\right]_{\mathrm{i}}$ kinetics assay in response to BIM-065 $(n=3)$. PRC, proportion of responsive cells showing changes in $\left[\mathrm{Ca}^{2+}\right]_{\mathrm{i}}$ in response to the treatment; PMR, percentage of maximum response; and time, time of response to treatment administration. Data are expressed as percent of vehicle-treated controls (set at 100\%) within experiment. Values represent the mean \pm SEM. ${ }^{*} p<0.05 ;{ }^{* *} p<0.01{ }^{* * *} p<0.001$ statistically significant differences. 




Fig. 2. AtT-20 corticotrope cell line. a Effect of BIM-065 $\left(10^{-7} \mathrm{M} ; n=5\right)$ of cell proliferation $(24-72 \mathrm{~h}$ treatment), measured by Alamar-blue reduction. b Representative Western Blots and quantification of levels of p-Akt/total Akt, $\mathrm{Bcl}-2 /$ ponceau, and p-ERK1/2/ total ERK1/2 in response to BIM-065 (10 $\left.{ }^{-7} \mathrm{M} ; n=3\right)$. Data are expressed as percent of vehicle-treated controls (set at $100 \%$ ) within experiment. Values represent the mean $\pm \mathrm{SEM}$. ${ }^{*} p<0.05 ;{ }^{* *} p<0.01$ statistically significant differences.

It should be mentioned that the expression levels of the truncated $\mathrm{SST}_{5}$ variants were also negligible in this set of samples.

Specifically, treatment with BIM-065 $\left(10^{-7} \mathrm{M}\right)$ significantly decreased cell viability in GHoma cell cultures after $72 \mathrm{~h}$ of incubation. Our data also revealed that the efficacy of BIM-065, octreotide, and pasireotide to reduce cell viability was comparable in GHoma cell cultures (35.6, 24.7, and 41.8\%, respectively; Fig. 3b) with respect to vehicle-treated control. BIM-065 also increased apoptosis (Fig. 3c) and strongly reduced GH secretion after $24 \mathrm{~h}$ of incubation (Fig. 3d). In line with this, we also had the opportunity to compare the effects of BIM-065 versus octreotide/pasireotide $\left(10^{-7} \mathrm{M}\right)$ in two independent GHoma cell cultures and found that all the compounds inhibited GH release (online suppl. Fig. 2).

Treatment with BIM-065 did not alter the mRNA expression levels of $\mathrm{GH}$ or other genes of interest mentioned above ( $\mathrm{SST}_{2}, \mathrm{SST}_{5}, \mathrm{D}_{2} \mathrm{~T}, \mathrm{D}_{2} \mathrm{~L}$ [Fig. 3e]; PTTG1, CDKN1B [online suppl. Fig. 5B]), except for CDK2, whose expression increased in response to BIM-065 compared to vehicle-treated control (online suppl. Fig. 5B). Finally, BIM-065 treatment clearly reduced $\left[\mathrm{Ca}^{2+}\right]_{\mathrm{i}}$ levels (32.74\% of reduction) in 2 out of the 3 GHomas analyzed, affecting the $30 \%$ of cells (Fig. 3f).

Expression Profile of $\mathrm{SST}_{2}, \mathrm{SST}_{5}$, and $\mathrm{D}_{2}$ and Effects of BIM-065 on NFPAs

NFPAs expressed high levels of $\mathrm{SST}_{2}, \mathrm{SST}_{5}$, and $\mathrm{D}_{2}$ and negligible levels of truncated SST ${ }_{5} \mathrm{TMD}_{4}$ and $\mathrm{SST}_{5} \mathrm{TMD} 5$, with relative order of $\mathrm{D}_{2} \mathrm{~T}>\mathrm{D}_{2} \mathrm{~L}>>\mathrm{SST}_{2}>\mathrm{SST}_{5}$ (Fig. 4a). Remarkably, in contrast to that found with ACTHomas and GHomas, none of the NFPAs analyzed in this study responded to BIM-065 in terms of cell viability (Fig. 4b; online suppl. Fig. 3). Conversely, similar to ACTHomas and GHomas, NFPA cells were clearly responsive to BIM065 in terms of increase in apoptosis (Fig. 4c) and reduce of CgA-secretion (Fig. 4d) after $24 \mathrm{~h}$ of incubation. Moreover, as we observed with ACTHomas and GHomas, treatment with BIM-065 did not produce any significant 


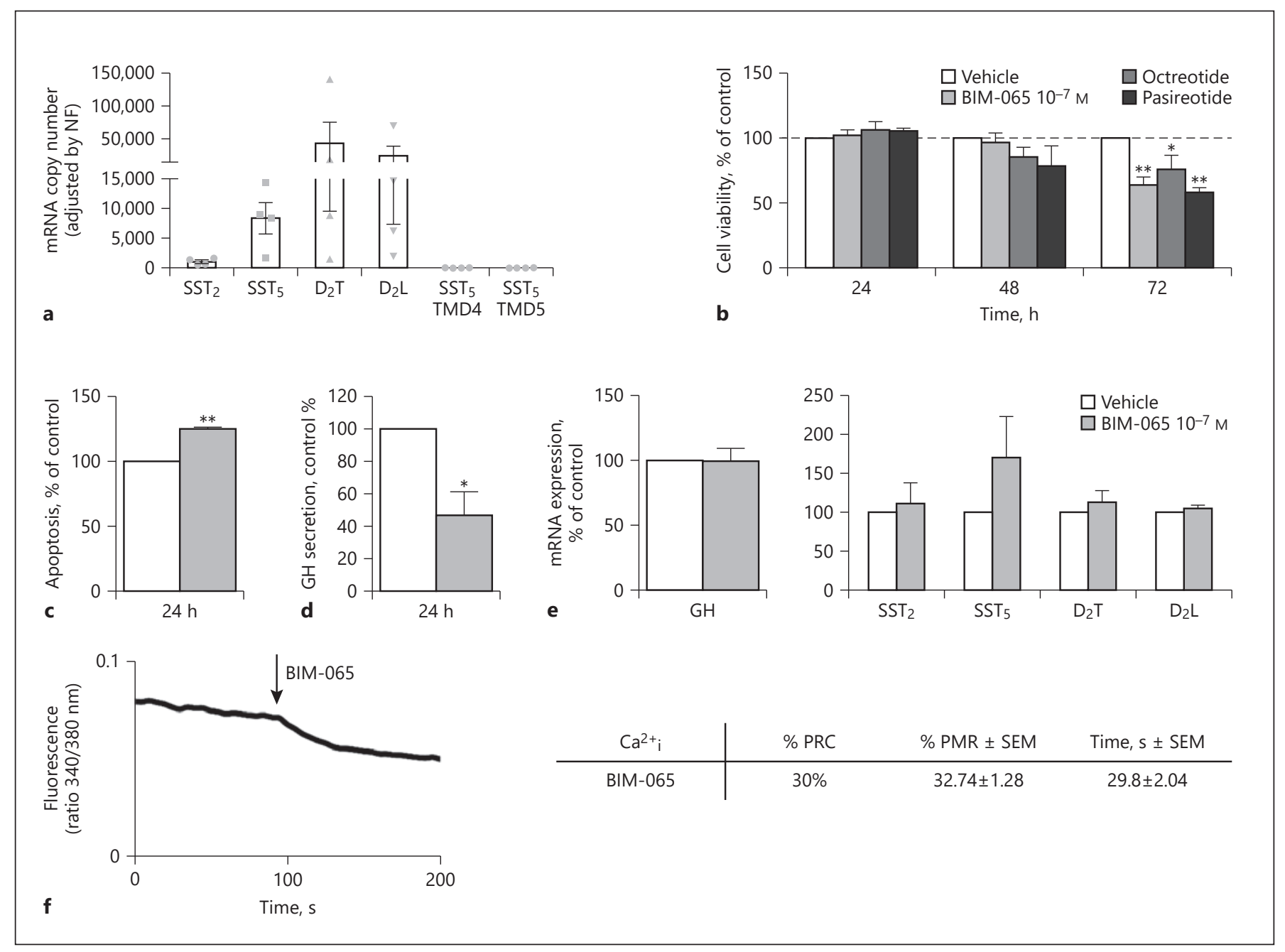

Fig. 3. GH-secreting adenomas. a Expression profile of $\mathrm{SST}_{2}, \mathrm{SST}_{5}$, $\mathrm{D}_{2}$ (total and long isoforms), $\mathrm{SST}_{5} \mathrm{TMD} 4$, and $\mathrm{SST}_{5} \mathrm{TMD} 5(n=4)$. b Effect of BIM-065, octreotide, and pasireotide on cell viability $\left(10^{-7} \mathrm{M} ; n=4 ; 24-72 \mathrm{~h}\right.$ treatment). c Effect of BIM-065 $(n=3)$ on apoptosis (24 h treatment). d Measurement of GH secretion (24 h treatment; $n=4)$. e mRNA expression levels of key genes in response to BIM-065 were measured by qPCR and adjusted by NF $(n=3)$. $\mathbf{f}$ Summarized table and representative profile of $\left[\mathrm{Ca}^{2+}\right]_{i}$

alteration in the mRNA expression levels of gonadotropin pituitary hormones (FSHB, LHB, or CGA), $\mathrm{SST}_{2}$, $\mathrm{SST}_{5}, \mathrm{D}_{2} \mathrm{~T}, \mathrm{D}_{2} \mathrm{~L}$ (Fig. 4e) or of the tumor markers PTTG1 or CDK2, while CDKN1B expression slightly decreased in response to BIM-065 compared to vehicle-treated control (online suppl. Fig. 5C). Finally, BIM-065 treatment also reduced $\left[\mathrm{Ca}^{2+}\right]_{\mathrm{i}}$ levels $(30.18 \%$ of reduction) in $2 / 3$ NFPAs analyzed but only in a limited percentage of NFPA cells $(27 \%)$ as compared to ACTHoma and GHoma cells (43.50 or $30.43 \%$, respectively; Fig. 4 f). kinetics assay in response to BIM-065 $(n=3)$. PRC, proportion of responsive cells showing changes in $\left[\mathrm{Ca}^{2+}\right]_{\mathrm{i}}$ in response to the treatment; PMR, percentage of maximum response; and time, time of response to treatment administration. Data are expressed as percent of vehicle-treated controls (set at $100 \%$ ) within experiment. Values represent the mean \pm SEM. ${ }^{*} p<0.05 ;{ }^{* *} p<0.01$ statistically significant differences.

\section{Expression Profile of $\mathrm{SST}_{2}, \mathrm{SST}_{5}$, and $\mathrm{D}_{2}$ and Effects of} BIM-065 on PRLomas

We also had the opportunity to analyze the expression levels of $\mathrm{SST}_{2}, \mathrm{SST}_{5}, \mathrm{D}_{2} \mathrm{~S}$, and truncated $\mathrm{SST}_{5}$ variants in two available PRLoma samples and to test the response to BIM-065. Specifically, PRLoma cells expressed high levels of $\mathrm{D}_{2}$ compared with $\mathrm{SST}_{2}$ and $\mathrm{SST}_{5}$ (and negligible levels of truncated $\mathrm{SST}_{5}$ variants), with relative order of $\mathrm{D}_{2} \mathrm{~T}>\mathrm{D}_{2} \mathrm{~L} \gg>>>\mathrm{SST}_{5}>\mathrm{SST}_{2}$ in PRLoma-1 and $\mathrm{D}_{2} \mathrm{~T}>\mathrm{D}_{2} \mathrm{~L} \gg \gg>\mathrm{SST}_{2}>\mathrm{SST}_{5}$ in PRLoma-2 (online suppl. 


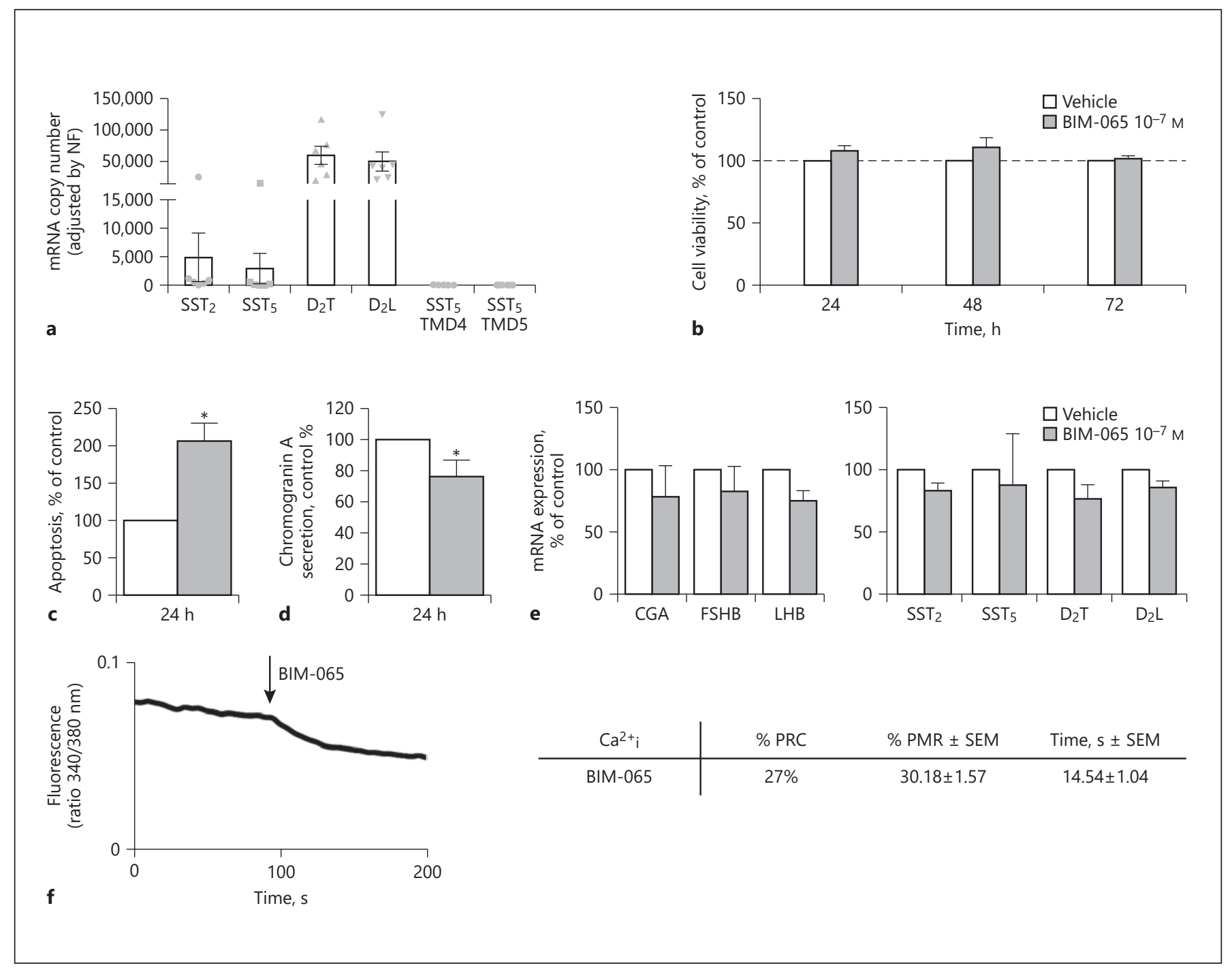

Fig. 4. Nonfunctioning pituitary adenomas. a Expression profile of $\mathrm{SST}_{2}, \mathrm{SST}_{5}, \mathrm{D}_{2}$ (total and long isoforms), $\mathrm{SST}_{5} \mathrm{TMD} 4$, and $\mathrm{SST}_{5} \mathrm{TMD} 5(n=3)$. b Effect of BIM-065 on cell viability $\left(10^{-7} \mathrm{M}\right.$; $n=8 ; 24-72$ h treatment), measured by Alamar-blue reduction. c Effect of BIM-065 $(n=3)$ on apoptosis ( $24 \mathrm{~h}$ treatment), measured by Caspase-Glo 3/7 assay. $\mathbf{d}$ Measurement of CgA secretion (24 h treatment; $n=3$ ), determined by commercial ELISA kit. e mRNA expression levels of key genes in response to BIM-065

Fig. 4A). BIM-065 decreased cell viability at all the doses tested after $72 \mathrm{~h}$ of incubation (online suppl. Fig. 4B) and this reduction was seemingly more pronounced than the effect of cabergoline (34.92 vs. $15.4 \%$, respectively; online suppl. Fig. 4C). A decrease of PRL secretion was also observed in response to BIM-065 compared with vehicletreated control after $24 \mathrm{~h}$ of incubation (online suppl. were measured by qPCR and adjusted by NF $(n=3)$. f Summarized table and representative profile of $\left[\mathrm{Ca}^{2+}\right]_{\mathrm{i}}$ kinetics assay in response to BIM-065 $(n=3)$. PRC, proportion of responsive cells showing changes in $\left[\mathrm{Ca}^{2+}\right]_{\mathrm{i}}$ in response to the treatment; PMR, percentage of maximum response; and time, time of response to treatment administration. Data are expressed as percent of vehicle-treated controls (set at 100\%) within experiment. Values represent the mean \pm SEM. ${ }^{*} p<0.05$ statistically significant differences. 


\section{Discussion/Conclusion}

In the present study, we have tested, for the first time and in a representative set of distinct PitNETs subtypes, the actions of a new peptidic chimeric compound, called BIM-065. BIM-065 has been designed with the same affinity to bind $\mathrm{SST}_{2}$, higher affinity to bind $\mathrm{SST}_{5}$, and slightly smaller affinity to bind $\mathrm{D}_{2}$ compared to the previous chimeric compound known as BIM-23A760 (binding affinity of BIM-065 in nM: 0.03 for $\mathrm{SST}_{2} ; 0.5$ for $\mathrm{SST}_{5}$; and 27.2 for $\left.\mathrm{D}_{2}[17,25,26]\right)$. Moreover, this second-generation dopastatin molecule has been designed with an improved chemical structure to avoid the generation of metabolites with potent dopaminergic activity as the one found to accumulate in patients enrolled in Phase IIb study in response to BIM-23A760 [17] and also to avoid the paradoxical stimulatory responses found in a small but relevant proportion of pituitary tumor cell populations after treatment with this latter compound [8].

Of particular novelty are the results showing that BIM065 decreases cell viability, increases apoptosis, and inhibits ACTH secretion in corticotropinomas, without significantly altering mRNA expression levels of the genes of interest at the times evaluated. To our knowledge, this is the first time that the effect of a chimeric compound is evaluated in detail in ACTH-secreting PitNETs. Although BIM-065 induced a comparable reduction of cell viability than octreotide at $10^{-7} \mathrm{M}$, the results achieved at $10^{-9} \mathrm{M}$ revealed a higher reduction of cell viability in response to BIM-065. Nevertheless, this observation should be taken with caution, as this comparison could only be tested in one ACTHoma. In contrast, pasireotide did not exert an inhibitory effect on cell proliferation despite the high expression levels of $\mathrm{SST}_{5}$ and also $\mathrm{SST}_{2}$, which might suggest that additional mechanisms distinct from the mere presence of a given receptor are required to exert an anti-proliferative effect. Indeed, several reports have described that the expression levels of other proteins such as filamin A, $\beta$-arrestins, or E-cadherin might be important for SSAs to exert their antitumor actions in pituitary tumors [45-49]. Interestingly, results of a previous study from our group demonstrated a decrease on ACTH secretion in response to BIM-23A760 in one ACTHoma analyzed [8], which is in accordance with the results of this report. In the same line, we observed a reduction on $\left[\mathrm{Ca}^{2+}\right]_{\mathrm{i}}$ levels in all ACTHomas tested in response to BIM065 , which is also in accordance with the $\left[\mathrm{Ca}^{2+}\right]_{\mathrm{i}}$ response observed in the previous study. Indeed, the reduction of $\left[\mathrm{Ca}^{2+}\right]_{\mathrm{i}}$ levels was similar in both studies $(26.4 \%$ of decrease in response to BIM- 065 versus $27 \%$ of decrease ob- served in response to BIM-23A760) but the percentage of responsive cells was higher with BIM-065 than with BIM-23A760 (43.50 vs. $24.0 \%$, respectively) [8]. Of note, in contrast with the previous study, we did not observe any stimulatory effect in response to BIM-065 in the ACTHomas tested. In addition, we also demonstrate that treatment with BIM-065 increased p-Akt and p-ERK1/2 levels and decreased Bcl-2 in AtT-20 cells. These 2 pathways are tightly linked to cell growth, proliferation, and survival in tumor pathologies, including PitNETs [50, 51], albeit they displayed a distinct temporal course: pAkt increased acutely, at $10 \mathrm{~min}$, while p-ERK1/2 levels raised after long-term, 24-h incubation. A similar stimulatory response in ERK1/2 levels has been previously reported in PitNET cells after treatment with BIM-23A760 and the dopaminergic agonist BIM-53097, which was mainly associated to an activation of the dopaminergic signaling through $\mathrm{D}_{2}$ that contributed to the antiproliferative effects of the 2 compounds in NFPA cell cultures [22]. Therefore, our results might suggest that the effects of BIM-065 on p-ERK1/2 and p-Akt proteins might be associated to a preferential activation of the $\mathrm{D}_{2}$ /dopaminergic-signaling. Moreover, the decrease in Bcl-2 levels supports the increase of apoptosis observed in response to BIM-065 in PitNETs. Therefore, the data presented provide novel evidence regarding how this new compound regulates some key intracellular signaling pathways in PitNETs cells. It should be noted that although a side-by-side study comparing BIM-065 and BIM-23A760 might have been interesting to make direct comparisons between both dopastatin compounds, the limitation of PitNET samples and the fact that BIM-23A760 was withdrawn from clinical development, prompted us to disregard this option, and to implement the direct, side-by-side comparison of BIM-065 with treatments currently used in medical practice (octreotide and pasireotide).

Results on GH-secreting PitNETs revealed that BIM065 also induced profound direct actions on this tumor type, where we observed a higher reduction of cell viability and a comparable increase of apoptosis compared with our previous results with BIM-23A760 in somatotropinomas [8]. In the case of GH secretion, we observed a 53.2\% of reduction of $\mathrm{GH}$ release, which is more striking than the decrease produced in response to BIM-23A760 or other chimeric compounds $\left(\mathrm{SST}_{2}-\mathrm{SST}_{5}\right.$ or $\left.\mathrm{SST}_{2}-\mathrm{D}_{2}\right)$ in somatotropinomas or $\mathrm{GH} 3$ pituitary cell line $[8,18,24,52]$. These results are in agreement with a very recent report showing that BIM-065 can reduce GH and IGF1 levels in healthy male volunteers with a safety and tolerability profile only limited by orthostatic hypotension [53]. On the
78

Neuroendocrinology 2020;110:70-82 DOI: $10.1159 / 000500812$
Vázquez-Borrego et al. 
other hand, treatment with BIM-065 was not accompanied by decreased GH mRNA levels after long-term exposition $(24 \mathrm{~h})$ in human GH-secreting PitNETs, which is in contrast to our previous results with BIM-23A760 [8], but compares well with the results reported by Grusz$\mathrm{ka}$ et al. [24] in response to BIM-23A760 and BIM23A761. Comparison of GH reduction between BIM-065 and SSAs did not show any relevant difference in the cases analyzed. Nevertheless, further experiments testing different BIM-065 doses and in additional tumor preparations will be necessary to unequivocally establish whether BIM-065 is more potent and efficacious than SSAs in somatotropinomas. An initial analysis of the possible mechanisms involved in the functional response observed in these tumors revealed that the new dopastatin evoked a clear reduction on $\left[\mathrm{Ca}^{2+}\right]_{i}$ levels, which also agrees with the predominant inhibitory responses observed by our group in the face of BIM-23A760 [8]; yet, in clear discrepancy with that observed previously for BIM-23A760 in somatotropinomas [8], but in line with our present results in ACTHomas, we did not detect herein any stimulatory response from somatotropinoma cells.

It is currently rare to have access to PRLoma samples for in vitro testing, given, fortunately, to the frequent success of DAs treatment regimens to control or even cure this type of tumors. However, in the course of this study, we had the opportunity to test this compound on 2 PRLsecreting PitNETs. Interestingly, we observed clear differences in the response to BIM-065 and cabergoline in terms of cell viability between the 2 PRLomas analyzed, which could be due to their differential receptor expression pattern. Thus, the tumor that was highly responsive to BIM-065 expressed higher levels of $\mathrm{SST}_{5}$ compared to $\mathrm{SST}_{2}$ and higher levels (and similar between them) of both isoforms of $\mathrm{D}_{2}$, which is a comparable expression pattern to that found in the rest of functioning PitNETs analyzed. Furthermore, these data are in line with previous results reporting that dopaminergic contribution is more important for the response to chimeric compounds, such as BIM-23A760, than the expression of $\mathrm{SST}_{2}$ [54]. Consistent with previous results observed with chimeric compounds $[8,24]$, a profound decrease on PRL release was detected in response to BIM-065; whereas, in contrast with the data reported so far in human PRLomas, rat pituitary cell cultures and MMQ cell line $[8,24,52]$, no changes were found on PRL mRNA levels. Nonetheless, our results showing that BIM-065 is able to decrease PRL release compare favorably with a very recent report showing that this compound inhibited PRL levels in healthy male volunteers [53]. Obviously, additional experiments are necessary to confirm/complement the results obtained herein, and to explore the signaling pathways involved, particularly given the unexpected observation that the effects observed in PRLomas did not seem to be accompanied by parallel changes in $\left[\mathrm{Ca}^{2+}\right]_{i}$ dynamics.

In contrast to previous results from our group and others with other dopastatins $[8,21]$, NFPA primary cell cultures did not show relevant alterations in terms of cell viability in response to BIM-065. Yet, surprisingly, the treatment with BIM-065 did induce a clear increase on apoptotic rate and a significant decrease in $\mathrm{CgA}$ in all cases tested. Although the vast majority of observations suggest that the cell proliferation and programmed cell death are effectively coupled $[55,56]$, there are several studies showing an imbalance between cell proliferation/survival index and apoptosis in pathological conditions such as breast, lung, or colorectal cancer [57-59]. Nevertheless, this observation is both, clinically relevant for this difficult-to-treat type of tumor, and biologically intriguing, and therefore further studies are warranted to explore the reasons why cell proliferation and apoptosis are apparently uncoupled in response to BIM-065 in NFPA primary cell cultures.

In summary, our data provide compelling evidence demonstrating that BIM-065 can directly and profoundly alter cell function and behavior in the most relevant subtypes of PitNETs. While not universal for all tumor types, BIM-065 acted reducing cell viability, likely by increasing apoptosis, and inhibiting hormone secretion, mostly by reducing $\left[\mathrm{Ca}^{2+}\right]_{\mathrm{i}}$ levels. Importantly, in contrast to previous dopastatin, treatment with BIM-065 did not evoke any stimulatory action in the tumor cells analyzed, while the proportion of responsive tumors/cells was higher with this compound than with BIM-23A760, suggesting that this novel dopastatin is a more efficacious and specific chimeric compound that could become a useful tool in the future treatment of PitNETs. Indeed, this compound could be used to treat patients harboring NFPAs without a clear indication of surgical resection, patients with a tumor residue or with hormone hypersecretion persistence after transsphenoidal surgery or to control hormone hypersecretion and reduce tumor growth before surgery. In any case, further studies should be implemented to confirm and expand the original results provided herein, and a randomized clinical trial comparing BIM-065 with the pharmacological options currently available should be performed. Thus, this new generation chimeric compound may hopefully help to enhance the currently scarce pharmacological arsenal for the treatment of patients harboring PitNETs. 


\section{Acknowledgments}

We thank Ipsen Bioscience (Cambridge, MA, USA) for kindly providing us the compounds BIM-065 and cabergoline. We also thank Novartis for generously providing us the pasireotide compound.

\section{Statement of Ethics}

All techniques carried out in this study were conducted in accordance with the ethical standards of the Helsinki Declaration of the World Medical Association and with the approval of the University of Cordoba/IMIBIC and Ethics Committees from all the Hospitals involved in the study. Informed consent from each patient was obtained.

\section{Disclosure Statement}

E.V.-M., M.A.G.-M., A.S.-M., C.B.-A., J.P.C., and R.M.L. have received lecture fees and/or research grant support from Ipsen and Novartis. M.D.C. and T.L. are former employees of Ipsen. The rest of the authors have nothing to disclose.

\section{Funding Sources}

This work was supported by the following grants: Junta de Andalucía (CTS-1406, BIO-0139); Instituto de Salud Carlos III-FIS (co-funded by European Union [ERDF/ESF, "Investing in your future”; PI16/00264, and “Miguel Servet” Program CP15/00156]), Ministerio de Ciencia, Innovación y Universidades, (BFU201680360-R) and CIBERobn. Ciber is an initiative of Instituto de Salud Carlos III, Ministerio de Ciencia, Innovación y Universidades, Spain.

\section{Author Contributions}

Conception and design of research: M.C.V.-B., T.L., M.D.C., J.P.C., and R.M.L.; Performed experiments: M.C.V.-B., F.L.-L., A.C.F.-F., and A.D.H.-M.; Analyzed data: M.C.V.-B., A.C.F.-F., J.P.C., and R.M.L.; Interpreted results: M.C.V.-B., A.C.F.-F., M.D.G., M.D.C., J.P.C., and R.M.L.; Prepared figures: M.C.V.-B., A.C.F.-F., and R.M.L.; Acquisition of clinical/pathological data and samples: M.A.-G., E.V.-M., A.D.H.-M., C.B.-A., J.S., and A.S.; Wrote the manuscript: M.C.V.-B., M.D.G., J.P.C., and R.M.L.; Critically revised the manuscript and approved final version: M.C.V.-B., F.L.-L., M.A.-G., A.C.F.-F., E.V.-M., A.D.H.-M., C.B.A., J.S., T.L., M.D.G., A.S., M.D.C., J.P.C., and R.M.L.

\section{References}

1 Melmed S. Pathogenesis of pituitary tumors. Nat Rev Endocrinol. 2011 May;7(5):257-66.

2 Mete O, Lopes MB. Overview of the 2017 WHO Classification of Pituitary Tumors. Endocr Pathol. 2017 Sep;28(3):228-43.

3 Asa SL, Ezzat S. The pathogenesis of pituitary tumors. Annu Rev Pathol. 2009;4(1):97-126.

4 Leon-Carrion J, Martin-Rodriguez JF, Madrazo-Atutxa A, Soto-Moreno A, Venegas-Moreno E, Torres-Vela E, et al. Evidence of cognitive and neurophysiological impairment in patients with untreated naive acromegaly. J Clin Endocrinol Metab. 2010 Sep; 95(9):4367-79.

5 Valassi E, Crespo I, Santos A, Webb SM. Clinical consequences of Cushing's syndrome. Pituitary. 2012 Sep;15(3):319-29.

6 Hofland LJ, Feelders RA, de Herder WW, Lamberts SW. Pituitary tumours: the sst/D2 receptors as molecular targets. Mol Cell Endocrinol. 2010 Sep;326(1-2):89-98.

7 Luque RM, Ibáñez-Costa A, Neto LV, Taboada GF, Hormaechea-Agulla D, Kasuki L, et al. Truncated somatostatin receptor variant sst5TMD4 confers aggressive features (proliferation, invasion and reduced octreotide response) to somatotropinomas. Cancer Lett. 2015 Apr;359(2):299-306.
8 Ibáñez-Costa A, López-Sánchez LM, Gahete $\mathrm{MD}$, Rivero-Cortés E, Vázquez-Borrego MC, Gálvez MA, et al. BIM-23A760 influences key functional endpoints in pituitary adenomas and normal pituitaries: molecular mechanisms underlying the differential response in adenomas. Sci Rep. 2017 Feb;7(1):42002.

9 Alhambra-Expósito MR, Ibáñez-Costa A, Moreno-Moreno P, Rivero-Cortés E, Vázquez-Borrego MC, Blanco-Acevedo C, et al. Association between radiological parameters and clinical and molecular characteristics in human somatotropinomas. Sci Rep. 2018 Apr;8(1):6173.

10 Günther T, Tulipano G, Dournaud P, Bousquet C, Csaba Z, Kreienkamp HJ, et al. International Union of Basic and Clinical Pharmacology. CV. Somatostatin Receptors: Structure, Function, Ligands, and New Nomenclature. Pharmacol Rev. 2018 Oct; 70(4):763-835.

11 Missale C, Nash SR, Robinson SW, Jaber M, Caron MG. Dopamine receptors: from structure to function. Physiol Rev. 1998 Jan;78(1): 189-225.

12 Theodoropoulou M, Stalla GK. Somatostatin receptors: from signaling to clinical practice. Front Neuroendocrinol. 2013 Aug;34(3): $228-52$.

13 Cuevas-Ramos D, Fleseriu M. Somatostatin receptor ligands and resistance to treatment in pituitary adenomas. J Mol Endocrinol. 2014 Jun;52(3):R223-40.
14 Peverelli E, Treppiedi D, Giardino E, Vitali E, Lania AG, Mantovani G. Dopamine and Somatostatin Analogues Resistance of Pituitary Tumors: Focus on Cytoskeleton Involvement. Front Endocrinol (Lausanne). 2015 Dec;6:187.

15 Rocheville M, Lange DC, Kumar U, Patel SC, Patel RC, Patel YC. Receptors for dopamine and somatostatin: formation of hetero-oligomers with enhanced functional activity. Science. 2000 Apr;288(5463):154-7.

16 Saveanu A, Jaquet P, Brue T, Barlier A. Relevance of coexpression of somatostatin and dopamine D2 receptors in pituitary adenomas. Mol Cell Endocrinol. 2008 May;286(12):206-13.

17 Culler MD. Somatostatin-dopamine chimeras: a novel approach to treatment of neuroendocrine tumors. Horm Metab Res. 2011 Nov;43(12):854-7.

18 Jaquet P, Gunz G, Saveanu A, Dufour H, Taylor J, Dong J, et al. Efficacy of chimeric molecules directed towards multiple somatostatin and dopamine receptors on inhibition of $\mathrm{GH}$ and prolactin secretion from GH-secreting pituitary adenomas classified as partially responsive to somatostatin analog therapy. Eur J Endocrinol. 2005 Jul;153(1):135-41. 
19 Jaquet P, Gunz G, Saveanu A, Barlier A, Dufour $\mathrm{H}$, Taylor J, et al. BIM-23A760, a chimeric molecule directed towards somatostatin and dopamine receptors, vs universal somatostatin receptors ligands in $\mathrm{GH}$-secreting pituitary adenomas partial responders to octreotide. J Endocrinol Invest. 2005;28(11 Suppl):21-7.

20 Culler MD, Dong JZ, Taylor JE, Touvay C, Teillot M, Marsais J, et al. The somatostatindopamine chimeric molecule, BIM-23A760, is highly efficacious in suppressing GH in normal, cynomolgus monkeys (Macaca fascicularis). Proceedings of the 88th Annual Meeting of the Endocrine Society, Philadelphia, PA, USA; Abstract O9-6. 2006.

21 Florio T, Barbieri F, Spaziante R, Zona G, Hofland LJ, van Koetsveld PM, et al. Efficacy of a dopamine-somatostatin chimeric molecule, BIM-23A760, in the control of cell growth from primary cultures of human non-functioning pituitary adenomas: a multi-center study. Endocr Relat Cancer. 2008 Jun;15(2):583-96.

22 Peverelli E, Olgiati L, Locatelli M, Magni P, Fustini MF, Frank G, et al. The dopamine-somatostatin chimeric compound BIM-23A760 exerts antiproliferative and cytotoxic effects in human non-functioning pituitary tumors by activating ERK $1 / 2$ and $\mathrm{p} 38$ pathways. Cancer Lett. 2010 Feb;288(2):170-6.

23 Gatto F, Barbieri F, Gatti M, Wurth R, Schulz $\mathrm{S}$, Ravetti JL, et al. Balance between somatostatin and D2 receptor expression drives TSH-secreting adenoma response to somatostatin analogues and dopastatins. Clin Endocrinol (Oxf). 2012 Mar;76(3):407-14.

24 Gruszka A, Culler MD, Melmed S. Somatostatin analogs and chimeric somatostatindopamine molecules differentially regulate human growth hormone and prolactin gene expression and secretion in vitro. Mol Cell Endocrinol. 2012 Oct;362(1-2):104-9.

25 Halem HA, Datta R, Bastille A, Beech J, Marques M, Patel S, et al. A Novel Somatostatin-Dopamine Chimeric Compound Induces Dose-Related Suppression of GHRH-Stimulated Growth Hormone Secretion and Increases Insulin Sensitivity in Normal Rats. Endocrine Society's 98th Annual Meeting and Expo Boston, USA. 2016;Abstract SUN-502.

26 Saveanu AD, Zhang S, Shen Y, Dong JZ, Graillon T, Desfilles C, et al. Novel Somatostatin-Dopamine Chimeric Compound Demonstrates Superior Efficacy in Suppressing Growth Hormone Secretion from Human Acromegalic Tumors Partially Responsive to Current Somatostatin and Dopamine Therapies. Endocrine Society's 98th Annual Meeting and Expo Boston, USA. 2016;Abstract SUN-531.

27 van Hoek M, Hofland LJ, de Rijke YB, van Nederveen FH, de Krijger RR, van Koetsveld PM, et al. Effects of somatostatin analogs on a growth hormone-releasing hormone secreting bronchial carcinoid, in vivo and in vitro studies. J Clin Endocrinol Metab. 2009 Feb; 94(2):428-33.
28 Ibáñez-Costa A, Rivero-Cortés E, VázquezBorrego MC, Gahete MD, Jiménez-Reina L, Venegas-Moreno E, et al. Octreotide and pasireotide (dis) similarly inhibit pituitary tumor cells in vitro. J Endocrinol. 2016 Nov; 231(2):135-45.

29 Luque RM, Ibáñez-Costa A, López-Sánchez LM, Jiménez-Reina L, Venegas-Moreno E, Gálvez MA, et al. A cellular and molecular basis for the selective desmopressin-induced ACTH release in Cushing disease patients: key role of AVPR1b receptor and potential therapeutic implications. J Clin Endocrinol Metab. 2013 Oct;98(10):4160-9.

30 Ibáñez-Costa A, Gahete MD, Rivero-Cortés E, Rincón-Fernández D, Nelson R, Beltrán M, et al. In1-ghrelin splicing variant is overexpressed in pituitary adenomas and increases their aggressive features. Sci Rep. 2015 Mar; 5(1):8714.

31 Uphoff CC, Drexler HG. Detection of mycoplasma contaminations. Methods Mol Biol. 2013;946:1-13.

32 Durán-Prado M, Gahete MD, MartínezFuentes AJ, Luque RM, Quintero A, Webb $\mathrm{SM}$, et al. Identification and characterization of two novel truncated but functional isoforms of the somatostatin receptor subtype 5 differentially present in pituitary tumors. J Clin Endocrinol Metab. 2009 Jul;94(7):263443.

33 Schneider CA, Rasband WS, Eliceiri KW. NIH Image to Image J: 25 years of image analysis. Nat Methods. 2012 Jul;9(7):671-5.

34 Taboada GF, Luque RM, Bastos W, Guimarães RF, Marcondes JB, Chimelli LM, et al. Quantitative analysis of somatostatin receptor subtype (SSTR1-5) gene expression levels in somatotropinomas and non-functioning pituitary adenomas. Eur J Endocrinol. 2007 Jan;156(1):65-74.

35 Taboada GF, Neto LV, Luque RM, CórdobaChacón J, de Oliveira Machado E, de Carvalho DP, et al. Impact of gsp oncogene on the mRNA content for somatostatin and dopamine receptors in human somatotropinomas. Neuroendocrinology. 2011;93(1):40-7.

36 Neto LV, Machado EO, Luque RM, Taboada GF, Marcondes JB, Chimelli LM, et al. Expression analysis of dopamine receptor subtypes in normal human pituitaries, nonfunctioning pituitary adenomas and somatotropinomas, and the association between dopamine and somatostatin receptors with clinical response to octreotide-LAR in acromegaly. J Clin Endocrinol Metab. 2009 Jun;94(6):1931-7.

37 Durán-Prado M, Saveanu A, Luque RM, Gahete MD, Gracia-Navarro F, Jaquet P, et al. A potential inhibitory role for the new truncated variant of somatostatin receptor 5, sst5T$\mathrm{MD}$ 4, in pituitary adenomas poorly responsive to somatostatin analogs. J Clin Endocrinol Metab. 2010 May;95(5):2497-502.
38 Martins CS, Camargo RC, Saggioro FP, Neder L, Machado HR, Moreira AC, et al. P27/CDKN1B Translational Regulators in Pituitary Tumorigenesis. Horm Metab Res. 2016 Dec; 48(12):840-6.

39 Chen R, Duan J, Li L, Ma Q, Sun Q, Ma J, et al. mTOR promotes pituitary tumor development through activation of PTTG1. Oncogene. 2017 Feb;36(7):979-88.

40 Gruppetta M, Formosa R, Falzon S, Ariff Scicluna S, Falzon E, Degeatano J, et al. Expression of cell cycle regulators and biomarkers of proliferation and regrowth in human pituitary adenomas. Pituitary. 2017 Jun;20(3): 358-71.

41 Stojilković SS, Izumi S, Catt KJ. Participation of voltage-sensitive calcium channels in pituitary hormone release. J Biol Chem. 1988 Sep; 263(26):13054-61.

42 Martínez-Fuentes AJ, Moreno-Fernández J, Vázquez-Martínez R, Durán-Prado $M$, de la Riva A, Tena-Sempere M, et al. Ghrelin is produced by and directly activates corticotrope cells from adrenocorticotropin-secreting adenomas. J Clin Endocrinol Metab. 2006 Jun; 91(6):2225-31.

43 Venegas-Moreno E, Vazquez-Borrego MC, Dios E, Gros-Herguido N, Flores-Martinez A, Rivero-Cortés E, et al. Association between dopamine and somatostatin receptor expression and pharmacological response to somatostatin analogues in acromegaly. J Cell Mol Med. 2018 Mar;22(3):1640-9.

44 Wildemberg LE, Vieira Neto L, Costa DF, Nasciutti LE, Takiya CM, Alves LM, et al. Validation of immunohistochemistry for somatostatin receptor subtype $2 \mathrm{~A}$ in human somatotropinomas: comparison between quantitative real time RT-PCR and immunohistochemistry. J Endocrinol Invest. 2012 Jun;35(6):580-4.

45 Peverelli E, Giardino E, Treppiedi D, Catalano R, Mangili F, Locatelli M, et al. A novel pathway activated by somatostatin receptor type 2 (SST2): inhibition of pituitary tumor cell migration and invasion through cytoskeleton protein recruitment. Int J Cancer. 2018 May;142(9):1842-52.

46 Coelho MC, Vasquez ML, Wildemberg LE, Vázquez-Borrego MC, Bitana L, Camacho $\mathrm{AH}$, et al. Clinical significance of filamin $\mathrm{A}$ in patients with acromegaly and its association with somatostatin and dopamine receptor profiles. Sci Rep. 2019 Feb;9(1):1122.

47 Gatto F, Biermasz NR, Feelders RA, Kros JM, Dogan F, van der Lely AJ, et al. Low beta-arrestin expression correlates with the responsiveness to long-term somatostatin analog treatment in acromegaly. Eur J Endocrinol. 2016 May;174(5):651-62.

48 Venegas-Moreno E, Flores-Martinez A, Dios E, Vazquez-Borrego MC, Ibañez-Costa A, Madrazo-Atutxa A, et al. E-cadherin expression is associated with somatostatin analogue response in acromegaly. J Cell Mol Med. 2019 May;23(5):3088-96. 
49 Coelho MC, Vasquez ML, Wildemberg LE, Vázquez-Borrego MC, Bitana L, Camacho $\mathrm{AH}$, et al. Molecular evidence and clinical importance of $\beta$-arrestins expression in patients with acromegaly. J Cell Mol Med. 2018 Apr; 22(4):2110-6.

50 Lee M, Wiedemann T, Gross C, Leinhäuser I, Roncaroli F, Braren R, et al. Targeting PI3K/ mTOR Signaling Displays Potent Antitumor Efficacy against Nonfunctioning Pituitary Adenomas. Clin Cancer Res. 2015 Jul;21(14): 3204-15.

51 Roof AK, Gutierrez-Hartmann A. Consider the context: Ras/ERK and PI3K/AKT/mTOR signaling outcomes are pituitary cell type-specific. Mol Cell Endocrinol. 2018 Mar;463:87-96.
52 Gruszka A, Ren SG, Dong J, Culler MD, Melmed S. Regulation of growth hormone and prolactin gene expression and secretion by chimeric somatostatin-dopamine molecules. Endocrinology. 2007 Dec;148(12): 6107-14.

53 de Boon WM, van Esdonk MJ, Stuurman FE, Biermasz NR, Pons L, Paty I, et al. A Novel Somatostatin-Dopamine Chimera (BIM23B065) Reduced GH Secretion in a First-in-Human Clinical Trial. J Clin Endocrinol Metab. 2019 Mar;104(3):883-91.

54 Cuny T, Mohamed A, Graillon T, Roche C, Defilles C, Germanetti AL, et al. Somatostatin receptor sst2 gene transfer in human prolactinomas in vitro: impact on sensitivity to dopamine, somatostatin and dopastatin, in the control of prolactin secretion. Mol Cell Endocrinol. 2012 May;355(1):106-13.
55 Pucci B, Kasten M, Giordano A. Cell cycle and apoptosis. Neoplasia. 2000 Jul-Aug;2(4):2919.

56 Evan GI, Vousden KH. Proliferation, cell cycle and apoptosis in cancer. Nature. 2001 May;411(6835):342-8.

57 Hao X, Du M, Bishop AE, Talbot IC. Imbalance between proliferation and apoptosis in the development of colorectal carcinoma. Virchows Arch. 1998 Dec;433(6):523-7.

58 Liu S, Edgerton SM, Moore DH 2nd, Thor AD. Measures of cell turnover (proliferation and apoptosis) and their association with survival in breast cancer. Clin Cancer Res. 2001 Jun;7(6):1716-23.

59 Mattern J, Volm M. Imbalance of cell proliferation and apoptosis during progression of lung carcinomas. Anticancer Res. 2004 NovDec;24(6):4243-6. 